\section{Isolated Metastasis of Pancreas due to Endometrial Carcinoma}

Sir,

Almost $2 \%$ of pancreatic malignancies are metastases of different primary cancers. ${ }^{1}$ Isolated metastases of the pancreas are usually seen secondary to renal cell cancer, melanoma, colorectal, breast and lung cancer. ${ }^{1-3}$ A 61-year woman presented with vaginal bleeding and was diagnosed as endometrial carcinoma (EC). Computerised tomography (CT) showed a polypoid $7.5 \mathrm{~cm}$ diameter lesion in the posterior wall of the uterus, showing deep invasion into the myometrium. Moreover, CT showed a $2.7 \times 2.9 \mathrm{~cm}$ mass located in the corpus of pancreas with appearance of chronic pancreatitis and dilated pancreatic duct (Figure 1). Laboratory tests were normal with tumor markers of CA 125: $12.17 \mathrm{U} / \mathrm{mL}$ (normal range: $0-35$ ), and CA 19-9: $12.59 \mathrm{U} / \mathrm{mL}$ (normal range: 0-27). Debulking surgery was performed. Perioperatively, wedge biopsy was taken from the pancreatic mass. Pancreatic resection was not performed due to the patient's request. Postoperative follow-up was uneventful. Histopathological examination revealed EC of uterus measuring $7 \times 5 \times 5 \mathrm{~cm}$ with no lymphatic, vascular or myometrial invasion and it was high grade III. Thirty-six lymph nodes were removed and all of them were free of malignancy. Pancreatic wedge biopsy was compatible with metastasis of EC.

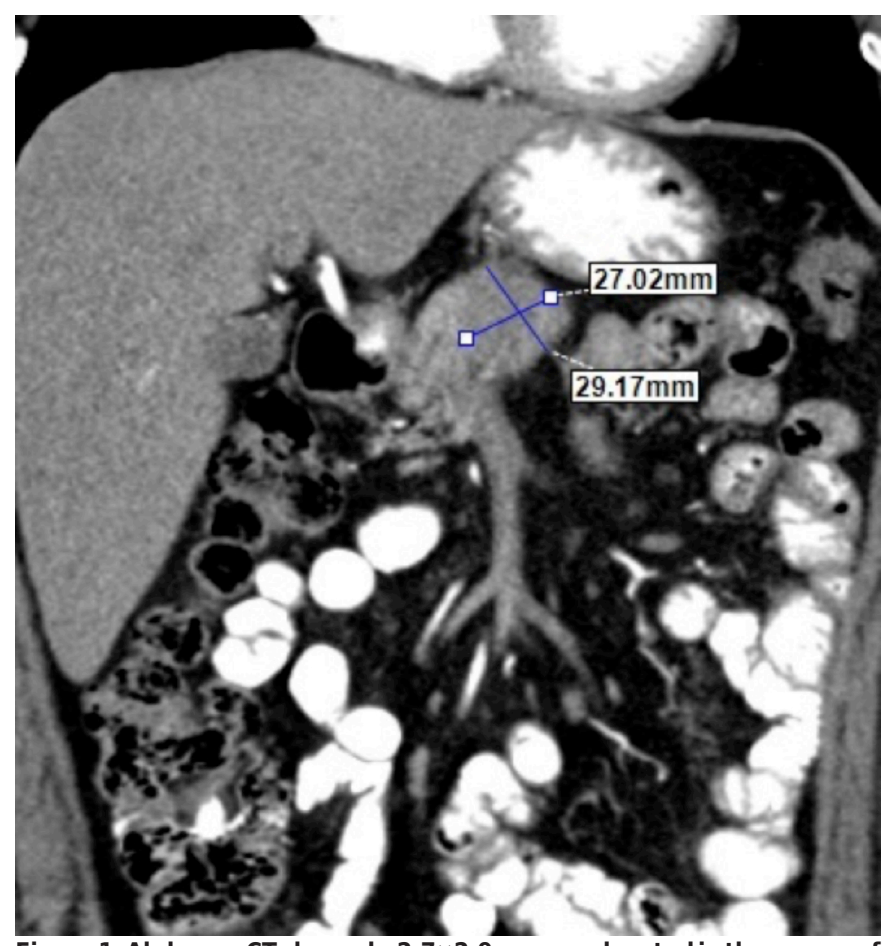

Figure 1: Abdomen CT showed a $2.7 \times 2.9 \mathrm{~cm}$ mass located in the corpus of pancreas with appearance of chronic pancreatitis and dilated pancreatic duct.
In the postoperative period, she received adjuvant chemotherapy. The patient was followed for 29 months after surgery and no signs of recurrence were detected.

Isolated metastases due to EC have been reported in four cases, who had previous surgery due to endometrial or cervical carcinoma. There is no known pathophysiological etiology for isolated pancreatic metastasis without lymph node involvement.

Although surgical treatment of metastatic pancreatic lesions has been shown to be safe and applicable in high-volume clinical centres, pancreatic resections are associated with high morbidity and mortality rates. ${ }^{1,2}$ However, some researchers have reported that patients who have been operated for isolated pancreatic metastasis have a longer survival time than those who have been operated for primary pancreatic cancer. ${ }^{1,4}$

Therefore, if the surgical risk is admissible, primary tumor-related residual cancer is not expected, that is, $\mathrm{R} 0$ resection is performed, surgery can be performed for isolated metastasis of the pancreas in the absence of extensive metastatic disease. ${ }^{2}$ As there is scarce data related to isolated pancreatic metastasis in EC, management should depend on clinician's discretion according to extent of the disease, patients' age and general condition, presence of comorbidities etc. Such patients should always be discussed in multidisciplinary tumor boards.

\section{CONFLICT OF INTEREST:}

No potential conflict of interest was reported by the authors.

\section{AUTHORS' CONTRIBUTION:}

SDA: Designed this study, prepared radiological images and wrote the manuscript.

GA: Participated in the surgical treatment of the patient, collected the patient's data and helped draft the study.

IS, CT: Participated in the design, coordination and helped draft the study.

All authors have read and approved the article.

\section{REFERENCES}

1. Sperti C, Moletta L, Patanè G, Metastatic tumors to the pancreas: The role of surgery, World J Gastrointest Oncol 2014; 6(10):381-92.

2. Yagi T, Hashimoto D, Taki K, Yamamura K, Chikamoto A, Ohmuraya $M$, et al. Surgery for metastatic tumors of the pancreas. Surgical Case Reports 2017; 3:31.

3. Ogawa H, Tsujie M, Miyamoto A, Yasui M, Ikenaga $M$, Hirao $M$, et al. Isolated pancreatic metastasis from uterine cervical cancer: A case report. Pancreas 2011; 40(5):797-8.

4. Blazer DG, Ramirez PT, Wang H, Fleming JB. Distal pancreatectomy for isolated metastasis of endometrial carcinoma to the pancreas jop. J Pancreas 2008; 9(1): 56-60. 
Semra Demirli Atici, Goksever Akpinar, Ismail Sert and Cem Tugmen

Department of General Surgery, University of Health Sciences, Tepecik Training and Research Hospital, Turkey

Correspondence to: Dr. Semra Demirli Atici, Department of
General Surgery, University of Health Sciences, Tepecik Training and Research Hospital, Turkey

E-mail: smrdemirli@hotmail.com

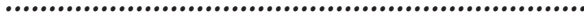

Received: January 08, 2020; Revised: February 19, 2020; Accepted: March 02, 2020

DOI: https://doi.org/10.29271/jcpsp.2020.12.1362 